\title{
Economic assessment of flood damage
}

\author{
Tatyana Miroshnikova ${ }^{1, *}$ \\ ${ }^{1}$ Vladivostok State University of Economy and Service, Gogolya str., 41, Vladivostok, 690014, \\ Russia
}

\begin{abstract}
Flooding is a natural hazard. In this regard, the topic of floodprone area management is being actively explored. The study of this issue is a combination of two aspects - environmental and economic. The economic assessment of the consequences of flooding is a single cost model based on an economic criterion. Characteristics such as flooding depth, flooding duration and flooding rate have the greatest influence on the severity of subsequent damage. Standard damage tables are usually based on some damage versus flooding depth. Assuming that the conceptual basis for estimating damages is the same, the expected damages from flooding might be expected to vary between two countries if the flood characteristics are different and the damageability of properties varies between the two countries. The main factors identified by the authors in the course of the study, influencing the amount of damage from flooding, are: flood resistance group; existing physical wear and tear; flooding level. The damage is considered as a percentage of the decrease in the real value of the object. To improve the accuracy of determining flood damage, a multivariate regression analysis tool with the interdependence of influencing factors was selected. It should be noted that the most significant factor is the level (depth) of flooding. The factor of the flood resistance group, which depends on the capital group of the object, seems to be less significant. The least significant factor is the degree of physical deterioration of the object.
\end{abstract}

\section{Introduction}

Flooding is a dangerous natural phenomenon, a possible source of an emergency situation if flooding of an area with water causes material damage, damages the health of the population or leads to the death of people, farm animals and plants.

The management of flood-prone areas is the most intensively researched and actively studied in the UK, USA, Japan, Germany and Australia. This model is a combination of two aspects - environmental and economic. However, flood management is a single cost model based on an economic criterion for assessing the effectiveness of the ratio of capital investment to flood losses.

The application of "standard", representative, or average data to the assessment of the losses from a particular flood always carries with it some degree of error. Within a single

\footnotetext{
* Corresponding author: tanmir12@mail.ru
} 
universe of flood events, these losses will follow some distribution about some central tendency estimator of expected flood losses. Random error in predicting the economic losses resulting from specific flood at one specific location is therefore both inevitable and acceptable. What it is required to avoid is systemic error: as represented by a consistent pattern of over - or under-estimating the economic consequences of a series of floods at that same location [1].

In principle, given the objective of minimizing systemic error, the issue of the transferability of standard flood loss estimation data between countries is no different to that of the transfer of such data between regions or locations within a city. However, a country or community may choose to ignore on equity grounds, when making investment decisions, those systemic errors which are a solely the result of differences in wealth between areas. A different country should not, however, ignore such a systemic difference between it and the country which is the source of the data.

Assuming that the conceptual basis for estimating damages is the same, the expected damages from flooding might be expected to vary between two countries if the flood characteristics are different and / or the damageability of properties varies between the two countries [2].

\section{Materials and Methods}

The characteristics of flooding which are conventionally believed to determine the severity of the consequent damages are:

- the depth of flooding;

- the duration of flooding;

- the velocity of flooding; and

. the sediment load carried on the flood waters and deposited with the retreat of flooding.

The depth of flooding in a property is usually considered to have the greatest effect on the severity of the consequent damages. Therefore, standard damage tables are usually based on some depth-damage relationship [3].

Duration has a clear effect on indirect losses because these are time dependent: the value of lost production depends both upon the time taken to get the plant back into production and the duration of the period when the plant is flooded. Similarly, traffic delays are a function of the duration of road closure. In consequence, the ratio of indirect losses to direct losses may be dramatically different for long duration floods compared to short duration floods

The velocity of the flood waters has a significant effect on damageability causing damage through: undermining the foundations of the property; simple pressure effects; and battering damage as a result of the material borne on the flood waters. Structural failure is the most important potential consequence of high velocity flooding, not least because of the risk of loss of life. Some relationships between the effects of depth and velocity on the likelihood of structural failure have been derived.

The research conducted by the author speaks of significant foreign experience in the field of flood management. The UK experience confirms that the chronology of water management is part of the chronology of economic analysis. The fundamental ideas of costbenefit analysis, as well as other valuation methods, including discounting, are still in use, even after ten years of use. Estimates of depth-damage curves in different countries. The studies to develop such curves in different countries have used somewhat different approaches. These differ in three different ways. The United States and Japan in particular have adopted unitary loss curves where losses are expressed as a proportion of the value of the building and its contents. In the UK and Australia, «depth-damage» curves of losses per square meter of built area or per building have been developed. Secondly, the loss data 
itself may be derived from statistics of actual compensation claims; interviews with flood victims; or by specialist assessors. The inherent variability of losses over different combinations of flood characteristics and between different properties means that very large samples are required if average or standard damage data is to be compiled on the basis of actual flood events [4].

The nature and direction of potential errors of estimation are different in each case.

Actual compensation payments are likely to be biased upwards where flood victims are articulate and downwards when they are disadvantaged. Flood victims are also not thought to appreciate all of the hidden damage to properties which may be caused by flooding. Flood victims may further have problems disentangling replacement costs for contents from indemnity costs. Some loss adjusters also see their job apparently as minimising the pay-out to the insured household. Finally, structural damages will be artificially underestimated if the household, family or friends undertake some of the repair work using their own labour. If there is any systematic tendency to use self-help according to household income or by other characteristic of the household, then the flood loss estimates obtained will also be biased in this way.

Thirdly, the depth-damage curves may be expressed either as a table of losses against depths or as a mathematical curve. A variety of mathematical functions have been adopted varying from simple linear forms to complex functions. A priori, some expected features of the function can be defined:

there will be a discontinuity between floors;

the curve will saturate at extreme depths and thus tend to be asymptotic to some value or percentage loss value at extreme depths; and

the curve will be steep at shallow depths to reflect damage to floors and floor

coverings [5].

Beyond that, however, there is no theoretical reason to expect any one functional form and the problem is a statistical one of fitting a curve to some set of data. James and Lee (1971) proposed that for shallow flooding:

$$
\text { damages }=\text { K.M.h }
$$

where.

$\mathrm{K}$ is an empirically derived coefficient (at averages about 0.044 )

$\mathrm{M}$ is the market value of the property; and;

$\mathrm{h}$ is the depth of flooding in feet.

For deeper flooding, the functional form of curve was argued to be non-linea (Figure 1). 


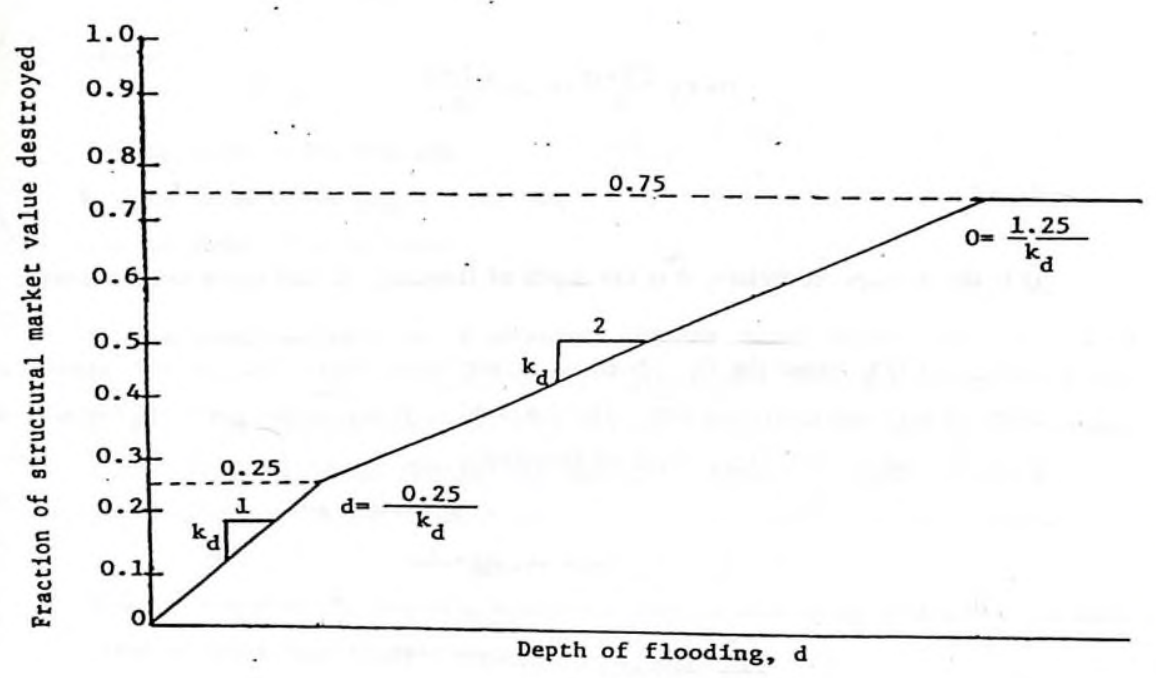

Fig.1 Hypothetical depth-damage curve (Source: James and Lee 1971).

Torterotot, Kauark-Leite and Roche (1992) fitted a linear unitary proportional loss function to interview data from 415 households in 8 urban and/or suburban areas of France, largely in order to illustrate the impacts of responses on damages [6].

Although Statistical robust, linear functions are unlikely to appropriate except over a very limited range of depths of flooding. It is not unreasonable; for example, anticipate points where the gradient of the curve changes rapidly at some depths. Thus, Bhavnagri and Bugliarello (1965) proposed a sine function

$$
D=K\left(\begin{array}{c}
I I * d \\
b
\end{array}+\sin \begin{array}{c}
I I * d \\
b
\end{array}\right)
$$

$\mathrm{D}$ is the damage in dollars; $\mathrm{d}$ is the depth of flooding; $\mathrm{K}$ and $\mathrm{b}$ are coefficients.

Aitkens (1975) tested the fit of both linear and logarithmic functions for residential contents and smictural loss data. The logarithmic function was preferred because it gave zero losses for a zero depth of flooding:

$$
\begin{aligned}
& \mathrm{D}_{\mathrm{s}}=203 * F H^{0.58 * F A^{0.413}} \\
& \mathrm{D}_{\mathrm{c}}=56.4 * F H^{0.517 * F A^{0.645}}
\end{aligned}
$$

where: Ds, is structural damage; Dc is contents damage;

FH is flood height above floor level (metres); and

$\mathrm{FA}$ is the floor area in square metres

\section{Results}

Comparison of the depth-damage curves for residential properties shows remarkably close approximations in those cases, where functional torn fitting has not been attempted, over depths up to about 1.2 metres at which damages, in some cases, are not thought greatly to increase with depth. Indeed, given the differences in the predominant form of construction in the countries, the similarity might be regarded as suspicious since there may be expected 
to be both differences in the characteristics of flooding in the different countries as well as in the property at risk.

However, the similarity is in the shape of curve and not necessarily in the location of the curve, the curves having been standardized to a proportional loss ratio centred on the losses at $60 \mathrm{cms}$ of flooding. From the discussion above, the expectation was that there was no reason for residential property to anticipate different shapes of depth-damage curves. Over 1.2 metres flooding, the data base for estimation the resulting curves is likely to be limited in some cases. Equally, it is likely that other flood characteristics (eg sediment load and velocity) may be correlated with the depth of flooding [7].

The US Federal Emergency Management Agency, in 2000, began developing a standardized methodology that is capable of assessing flood damage as well as economic and social losses. The work was carried out through an integrated Geographic Information System - GIS to provide the user with research in tabular and graphical format. GIS is an invaluable tool for flood assessment. An example is the processing of data on a large-scale flood in 1993 in the region of the Mississippi and Missouri rivers, which covered 10 states. One of the positive aspects has been the improvement in the development of information strategies designed to reduce risk and costs in the event of predicting future floods of potentially greater magnitude. Hydrological modeling and remote sensing were the most efficient tools for the analysis. The Earth Satellite Corporation developed 155 databases, following the operational definition of an aerial flood extension and the use of aerial photography. The combination of four satellite imagery, digital imagery, processing technology, differentiation of water surfaces in adjacent areas of the earth, and synchronization of peak flood ridges and radar data were critical to flood assessment [8].

Integration of international experience can provide the necessary assistance in developing measures to prevent and eliminate the consequences of emergencies caused by floods in Russia.

In terms of frequency of occurrence, area of distribution and total average annual material damage, floods in the territory of the Russian Federation rank first among natural disasters, and in terms of the number of human victims and specific material damage (per unit of affected area), they rank second after earthquakes.

The total area of flood-prone areas in Russia is about 400 thousand km2. Floods with catastrophic consequences affect an area of 150 thousand $\mathrm{km} 2$, which contains more than 300 cities, tens of thousands of villages and villages (settlements), more than 7 million hectares of agricultural land

Average long-term total damage from floods in the main water bodies of Russia (according to Rosvodresursy data), billion rubles

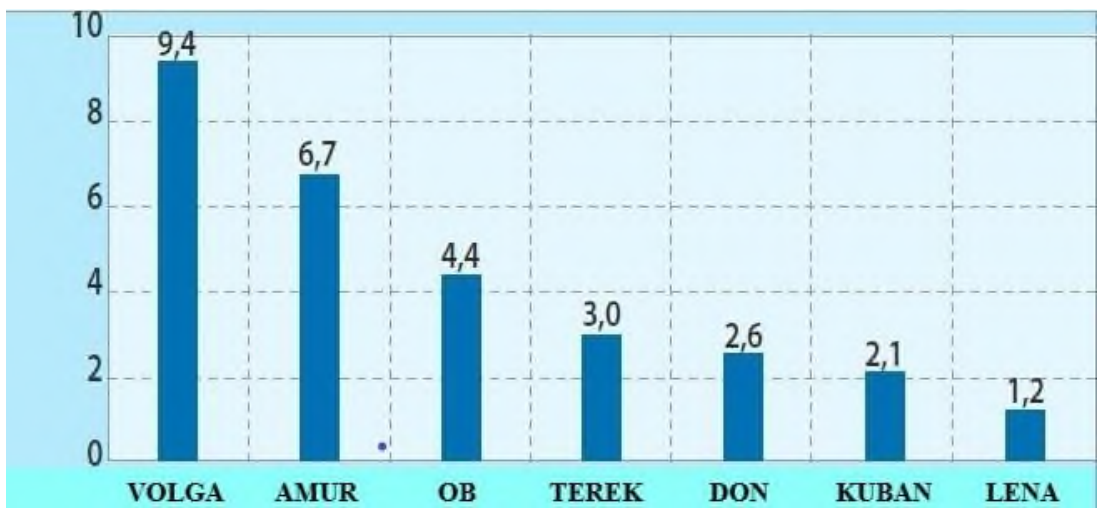

Fig 2. Average long-term total damage from floods in the main water bodies of Russia 
According to a study by the All-Russian Scientific Research Institute of Hydrometeorological Information - World Data Center (FGBU "VNIIGMI-MCD"), the total number of hazardous hydrological phenomena (floods, floods and mudflows) in the first decade of the XXI century. in Russia increased by 1.5 times compared to the $1990 \mathrm{~s}$.

\section{Discussion}

Let us present the result of a large-scale study on the economic assessment of flood damage. Flood damage is calculated as an increase in the physical deterioration of the object (physical destruction) due to the impact of the water environment, up to the complete destruction of the object. The damage is considered as a percentage of the decrease in the real value of the object [9].

The main factors affecting the amount of damage (degree of destruction) are:

- flood resistance group;

- existing physical wear and tear;

- flooding level.

To calculate the percentage (coefficient) of reduction (loss) of the real value of the property, the formula is used

$$
\mathrm{a}=\alpha_{1} * \mathrm{x}_{1}+\alpha_{2} * \mathrm{x}_{2}+\alpha 3 * \mathrm{x}_{3}
$$

where: $\alpha_{1}$ is the coefficient of influence of stability groups

$\alpha 2$ of the effect of object wear

$\alpha 3$ coefficient of influence of flooding level.

$\mathrm{x}_{1}$ flood resistance group

$\mathrm{x}_{2}$ existing physical wear (\%)

$\mathrm{x}_{3}$ flooding level (m)

The $\mathrm{x} 1$ and $\mathrm{x} 2$ values for each object are defined in the database, the $\mathrm{x} 3$ value is set each time during the calculation.

The coefficient of influence of the stability group depends on the capital group (dependence on the standard life of a property for civil and industrial buildings), that is, the type of materials used in the construction of the main structural elements (foundations, walls, floors) of buildings.

Taking into account the quality of the available information on objects, it is proposed to carry out damage calculations the following classification of real estate objects according to the degree of stability.

Table 1. Classification of real estate objects according to the degree of stability

\begin{tabular}{|l|l|l|l|}
\hline & \multicolumn{1}{|c|}{1 group } & \multicolumn{1}{|c|}{2 group } & \multicolumn{1}{|c|}{ group } \\
\hline foundation & $\begin{array}{l}\text { Reinforced } \\
\text { concrete, stone, } \\
\text { brick }\end{array}$ & $\begin{array}{l}\text { Reinforced } \\
\text { concrete, stone, } \\
\text { brick }\end{array}$ & Wooden \\
\hline walls & $\begin{array}{l}\text { Stone, brick, } \\
\text { reinforced concrete } \\
\text { panels }\end{array}$ & $\begin{array}{l}\text { Wooden, mixed } \\
\text { (brick and wood) }\end{array}$ & $\begin{array}{l}\text { Wooden, frame- } \\
\text { filling, panel board }\end{array}$ \\
\hline
\end{tabular}

The degree of stability of objects of the first group is maximum and decreases in the second group, and in the third group it has the lowest value.

Since there is no reliable data on the study of the degree of stability of real estate objects to the impact of the water environment, depending on the capital group, the inverse dependence of the influence of this factor on the amount of damage is accepted. 
A conventionally single value of the coefficient of influence of this factor on the magnitude of damage is assigned to the 3rd stability group (the least stable group) The first and second groups are conventionally assigned the values of the coefficients $1 / 3$ and $1 / 2$, respectively (based on the assumption that objects of the second group are twice as resistant to flooding objects of the third group, and objects of the first group are three times more stable than objects of the third group).

For the coefficient $\alpha 1$ (the coefficient of influence of the stability group), the following values are taken:

Table 2. The coefficient of influence of the stability group

\begin{tabular}{|l|l|l|l|}
\hline & 1 group & 2 group & 3 group \\
\hline$\alpha_{1}$ & $1 / 3$ & $1 / 2$ & 1 \\
\hline
\end{tabular}

General physical wear is the weighted average wear of the main structural elements and engineering equipment of the building (foundations and walls), their loss of their original qualities. It is assumed that over the years, the physical deterioration of the building increases more and more. In fact, as a result of major and current repairs, the growth rates of physical depreciation are decreasing. The wear of both buildings as a whole and of their individual elements occurs most intensively during the first period of operation (the first twenty-thirty years) and after 90-100 years.

In the process of wear, one can distinguish:

- section I - running-in period, increased wear;

- section II - the period of normal operation and slow wear, during which irreversible

deformations accumulate;

Section III - a period of accelerated wear, when it reaches a critical value and the question of dismantling the building arises.

Thus, the influence of the wear factor will be highest in sections I and III, and the least in section II.

A conventionally single value of the coefficient of influence of this factor on the amount of damage is assigned to objects with physical wear from $0 \%$ to $40 \%$ and to objects with physical wear from $50 \%$ to $100 \%$ (in these intervals, the increase in physical wear is approximately the same). For objects with physical wear from $40 \%$ to $50 \%$, a decrease in the growth rate of wear is expected. To carry out calculations on the example of a model section, a decrease in the rate of wear in this interval was taken (conventionally) by a factor of two. For coefficient $\alpha 2$ (coefficient of influence of object wear), the following values are taken:

Table 3. Coefficient of influence of object wear

\begin{tabular}{|l|l|l|l|}
\hline & $0 \%-40 \%$ & $40 \%-50 \%$ & $50 \%-100 \%$ \\
\hline a2 & 1 & $1 / 2$ & 1 \\
\hline
\end{tabular}

The effect of the level (depth) of flooding will depend on:

1 one floor building;

2 the presence or absence of a basement (basement height).

We classify buildings by the number of floors:

- one floor buildings;

- two-storey buildings;

- multistory buildings

The average (typical) height of one floor is approximately three meters. 
The degree of flooding (destruction) of buildings with a different number of floors at the same flood level will be different. If a one-story building is completely flooded, a two-story building will be flooded by $1 / 2$, a three-story building by $1 / 3$, and so on.

Consequently, the dependence of the influence of the degree of flooding of the building will be inversely proportional to the number of storeys of the building:

Number of storeys $=1 / \mathrm{n}$

where $\mathrm{n}$ is the number of floors in the building (number of storeys in the building).

The presence or absence of a basement floor will also affect the overall level of damage.

To take into account the factor of the presence of a basement, the most common basement heights for various types of buildings were selected:

1. lack of a basement;

2. basement floor up to 0.7 meters high;

3. basement floor with a height of 0.7 to 1.1 meters;

4. 4th ground floor with a height of more than 1.1 meters.

Taking into account the approximate average (typical) height of one floor, we determine the value of the "basement" factor:

Table 4. Average (typical) height of one floor

\begin{tabular}{|l|l|c|c|}
\hline Absence & Up to 0.7 meters & from $0.7 \mathrm{~m}$ to $1.1 \mathrm{~m}$ & More than 1.1 meter \\
\hline 0 & 0.23 & 0.30 & 0.37 \\
\hline
\end{tabular}

The total coefficient of the influence of the level (depth) of flooding (a3) on the property is taken to be equal to the product:

$$
a_{3}=1 / \beta_{1} \times\left(1-\beta_{2}\right)
$$

where: $\beta_{1}-$ number of storeys of the building;

B2 - factor of the presence or absence of a basement floor.

Since the formula of multivariate regression analysis was chosen to determine the damage from flooding, it seems necessary to determine the degree of influence on the final result (on the percentage of damage) of each of the factors.

The most significant factor is the level (depth) of flooding. It should have been given the highest weight.

The least significant factor is the degree of physical deterioration of the property.

To carry out an indicative calculation of flood damage for the facilities of the model area, the above factors were conditionally assigned the following weighting factors:

Table 5. Weighting factors

\begin{tabular}{|l|l|}
\hline Factor name & Weight coefficient \\
\hline (a1) influence of the stability group & 3.0 \\
\hline (a2) the effect of depreciation of the item & 0.5 \\
\hline (a3) effect of flooding level & 10.0 \\
\hline
\end{tabular}

The calculation formula will look like this:

$$
\mathrm{a}=3 \mathrm{a}_{1} *\left(\mathrm{X}_{1}\right)+0,5 \mathrm{a}_{2} *\left(\mathrm{X}_{2}\right)+10 \mathrm{a}_{3} *\left(\mathrm{X}_{3}\right)
$$

where: $\alpha 1$ is the coefficient of influence of stability groups:

$\alpha 2$ of the effect of object wear

$\alpha 3$ coefficient of influence of flooding level.

$\mathrm{x} 1$ flood resistance group

x 2 existing physical wear (\%) 
хз flooding level (m)

When calculating flood damage, objects are classified by risk zones and by the degree of flood resistance [10].

\section{Conclusion}

The problems of economic flood damage are largely determined by three levels. First, the level of economic and social development of the territory, measured in particular by such indicators and factors as the total gross product per square meter of territory, population density, the nature of settlement, average per capita income, the dependence of the territory's economy on the federal budget. Secondly, the specifics of the flooded area, the types and density of objects located on it: the degree of development of the territory, the number of industrial, agricultural, non-industrial facilities, the specific value of assets, the presence of hazardous industries on the territories, the system of the established nature management. Third, the feasibility and effectiveness of management measures from an economic, social and environmental point of view. There is a need to rank the types of economic activities according to the principle of their economic feasibility and social significance for areas regularly exposed to flooding. Flood management requires the use of "standard", representative or temporal data to estimate losses from a particular flood. We need to improve both, damage estimations and the quality of damage data since a good documentation and standardized collection and management of damage data are a prerequisite for the development of reliable damage models [11]. Public policy evaluations intend to support decisions such as flood risk zoning and cost-benefit analysis of structural flood defense. They take a broader perspective of assessing potentially all costs and benefits to the national or regional economy [12].

\section{References}

1. S. J. Appelbaum, Determination of Urban Flood Damage. Journal of the ASCE, Water Resources Division, 111(3), 269-282 (1985)

2. S A Davis, Business Depth-Damage Analysis Procedures. Research Report 85-R-5, Ft Belvoir, VA: Institute for Water Resources, US Corps of Engineers (1985)

3. M. A. Greenaway, D. I. Smith, ANUFLOOD Field Guide, Canberra: Centre for Resource and Environmental Studies, Australian National University (1983)

4. N. S. Grigg, O. J. Helweg, "State-of-the-art of estimating flood damage in urban areas". Water Resources Bulleting, 11(2), 379-390 (1975)

5. R. J. Higgins, An Economic Comparison of Different Flood Mitigation Strategies in Australia. Unpublished PhD Thesis, School of Civil Engineering, University of New South Wales (1981)

6. R. J. Higgins, D. K. Robinson, “The Assessment of Urban Flood Damages”, paper given at the Symposium on Hydrology and Water Resources, Adelaide (1980)

7. A. G. Homan, B. A. Waybur, study of Procedure in Estimating Flood Damage to Residential, Commercial and Industrial Properties in California, Menlo Park, CA.: Stanford Research Institute (1960)

8. J. Behzad, L. Roland, A rapid urban flood inundation and damage assessment model. Journal of Hydrology, 564, 1085-1098 (2018)

9. B. Merz, H. Kreibich, R. Schwarze, A. Thieken, Review article "Assessment of economic flood damage" Nat. Hazards Earth Syst. Sci., 10, 1697-1724 (2010) 
www.nat-hazards-earth-syst-sci.net/10/1697/2010/ (Last accessed 21.01.2021) doi:10.5194/nhess-10-1697-2010

10. D. I. Smith, Flood damage estimation - A review of urban stage damage curves and loss functions, Water SA, 20(3), 231-238 (1994)

11. J. Schwarz, H. Maiwald, Damage and loss prediction model based on the vulnerability of building types, 4th International Symposium on Flood Defence, Toronto, Canada (2008)

12. J. Ramirez, W. L. Adamowicz, K. W. Easter, T. Graham-Tomasi, Ex Post Analysis of Flood Control: Benefit-Cost Analysis and the Value of Information, Water Resour. Res., 24, 1397- 1405 (1988) 